\title{
Cross-Cultural Adaptation and Psychometric Properties of the Portuguese Version of the Aspiration Index (AI)
}

\author{
Susana Núñez-Rodriguez ${ }^{1}$ \\ Ana Paula Lazaretti de Souza \\ Sílvia Helena Koller \\ Universidade Federal do Rio Grande do Sul, Porto Alegre, RS, Brazil
}

\begin{abstract}
The aim of this study was to develop a cross-cultural adaptation version and to make a psychometric evaluation of the Aspiration Index (AI) for the Brazilian context. This instrument assesses the importance that individuals put in their life goals. Participants consisted of 971 Brazilian youth aged from 18 to 30 years old $\left(M_{a g e}=22.8 ; S D=3.4\right)$. The cultural adaptation showed that it was appropriated both at a cultural and linguistic level. The confirmatory factor analysis (CFA) demonstrated the adequacy of the original 11-factor model for the Brazilian context, and the multi-group CFA showed that this structure was invariant across different socio-economic groups. Furthermore, the multidimensional scaling modeling (MDS) replicated the results earlier studies, positing a two-dimension structure as representation of the data. With one dimension underlying the intrinsic (e.g., self-acceptance, affiliation) versus extrinsic goals (e.g., financial success, image); and the second dimension defined by the self-transcendent (e.g., spirituality) and the physical goals (e.g. health). These results suggest that the AI is a reliable measure to assess different types of life goals and can be used with the Brazilian population from different regions and socioeconomic levels.
\end{abstract}

Keywords: Goals, Self-Determination theory, Aspiration Index, AFC, cross-cultural research.

\section{Adaptação Transcultural e Propriedades Psicométricas da Versão em Português do Índice de Aspirações (IA)}

\section{Resumo}

O objetivo deste estudo foi desenvolver uma adaptação transcultural e uma avaliação psicométrica do Índice de Aspirações (IA) para o contexto brasileiro. Este instrumento avalia a importância que os indivíduos dão para diferentes metas na vida. Participaram 971 jovens brasileiros de 18 a 30 anos de idade $\left(M_{a g e}=22,8 ; D P=3,4\right)$. A adaptação transcultural demonstrou que o instrumento era adequado a nível linguístico e cultural. A análise fatorial confirmatória (AFC) mostrou a adequação do modelo original de 11 fatores para o contexto brasileiro, e a AFC multigrupo mostrou que esta estrutura permaneceu invariante para grupos de diferentes níveis socioeconômicos. Além disso, a análise de escalonamento multidimensional (MDS) replicou a estrutura bidimensional como uma representação gráfica dos dados. Com uma dimensão que subjaz às metas intrínsecas (i.e. autoaceitação, afiliação) versus as extrínsecas

\footnotetext{
Mailing address: Ramiro Barcelos, 2600, Office 104, Porto Alegre, RS, Brazil 90035-003. Phone: (51) 33085150. Fax: (51) 3241-0074. E-mail: susana.nunez@gmail.com

The research reported in this article was supported by a doctoral Grant from Program of Agreement-Student of Graduation Studies/Coordination for the Improvement of Higher Education (PEC-PG/Capes) to Susana Nuñez Rodriguez. The authors wish to thank prof. Tim Kasser and PhD. Wagner Lara for their valuable comments on an earlier version of this manuscript.
} 
(i.e. sucesso financeiro, imagem), e a segunda dimensão definida por metas de autotrascendência (i.e. espiritualidade) versus metas físicas (i.e. saúde). Os resultados sugerem que o IA é um instrumento confiável para avaliar diferentes tipos de metas e que pode ser usado com a população brasileira de diferentes regiões e níveis socioeconômicos.

Palavras-chave: Metas, Teoria da Autodeterminação, Índice de Aspirações, AFC, pesquisa transcultural.

\section{Adaptación Transcultural y Propiedades Psicométricas de la Versión en Portugués del Índice de Aspiraciones (IA)}

\section{Resumen}

El objetivo de este estudio fue desarrollar una adaptación transcultural y una evaluación psicométrica del Índice de Aspiraciones (AI) para el contexto brasileño. Este instrumento evalúa la importancia que los individuos dan a diferentes metas de vida. Participaron 971 jóvenes brasileños con edades entre $18 \mathrm{e}$ 30 años $\left(M_{a g e}=22.8 ; S D=3.4\right)$. La adaptación transcultural demostró que el instrumento era apropiado a nivel lingüístico y cultural. El análisis factorial confirmatorio (AFC) demostró la idoneidad del modelo original de 11 factores al contexto brasileño, y el AFC multigrupo demostró que esta estructura se mantuvo invariante para los distintos grupos socioeconómicos. Además, el análisis de escalonamiento multidimensional (MDS) replicó los resultados de estudios anteriores, postulando una estructura de dos dimensiones como representación gráfica de los datos. Con una dimensión que subyace a las metas intrínsecas (i.e., auto-aceptación, afiliación) y las metas extrínsecas (i.e., éxito financiero, imagen); y la segunda dimensión definida por metas de auto-trascendencia (i.e., espiritualidad) y metas físicas (i.e., salud). Por lo tanto, los resultados sugieren que el AI es una medida fiable para evaluar diferentes tipos de metas y se puede utilizar con la población brasileña de diferentes regiones y niveles socioeconómicos.

Palabras clave: Metas, Teoría de la Auto-determinación, Índice de Aspiraciones, AFC, investigación transcultural.

The aim of this study was to describe the cross-cultural adaptation process of the Aspiration Index (AI; Grouzet et al., 2005) to Brazilian-Portuguese and to investigate psychometric properties of the Brazilian version of the AI. The instrument assesses multiple sets of goals in different domains such as financial success, image, sense of community, among others, evaluating the importance of each specific goal and the chances people believe they have to achieve it.

The AI was developed based on studies by Kasser and Ryan aiming to identify how the content of some goals could have an effect in various psychological outcomes (Kasser \& Ryan, 1993, 1996, 2001). The initial hypothesis of these studies was that certain types of goals could be more closely related to psychological well-being and bring more benefits to the in- dividual, than others. To test this, the authors proposed a series of studies and compared two types of goals: the intrinsic and the extrinsic ones (Kasser \& Ryan, 1993, 1996). The intrinsic goals are aims valuable and satisfactory on their own, not depending on the approval or evaluation from others (Kasser, 2011; Vansteenkiste, Lens, \& Deci, 2006). Such goals would be the expression of growth and self-realization, and serve as primary factors of satisfaction of the basic psychological needs - as described by the Self Determination theory (SDT; Deci \& Ryan, 2000, 2012). Examples of intrinsic goals would be giving back something to the community, or goals for self-acceptance.

On the other hand, extrinsic goals are those that rely on an implicit reward or reconnaissance for their achievement. These goals do not provide satisfaction on their own, but the basis of their 
appeal is that their achievement could generate admiration or a sense of power and self-esteem (Kasser, 2011; Vansteenkiste et al., 2006). As examples of extrinsic goals, we could mention the search for financial success, in which the money or other possessions help portraying a sense of power or boost self-esteem.

Thus, the initial version of the AI, built upon these studies by Kasser and Ryan (1993, 1996), was composed by two groups of goals to represent: (a) intrinsic goals, represented by four subscales of self-acceptance, affiliation, sense of community, and health; and (b) extrinsic goals, represented by three sub-scales of financial success, popularity, and image. The results of those studies indicated that giving more importance to intrinsic aspirations was positively related to well-being indicators, self-actualization and vitality, and negatively associated with depressive symptoms and physical symptoms of anxiety. Conversely, giving more importance to extrinsic aspirations generated the opposite results.

However, after considering the contributions of other theoretical approaches and recent research, authors added new four goal groups to the current version of the AI. The first group corresponds to goals of "conformity", expressing the intention of people to fit in with others and with their environment and to meet the expectations and norms of their society (Cialdini \& Goldstein, 2004). The second group refers to goals of "safety", since according to the attachment theory (Van Ijzendoorn \& SagiSchwartz, 2008) and terror management theory (Burke, Martens, \& Faucher, 2010; Vail et al. 2012), to feel safe and secure in their environment is a powerful motivation for human beings. The third group assesses "hedonic" goals, considering that the pursuit of pleasure is natural for human beings (Deci \& Ryan, 2008). Finally, the fourth group corresponds to goals of "spirituality", which serve as a powerful motivator for people in different contexts, and sometimes used as a coping strategy (Emmons, 2003; Espíndula, Do Vale, \& Bello, 2010).

After adding these four subgroups of goals, Grouzet et al. (2005) conducted a psychometric study with 1,854 college students from 15 different countries to examine the validity and reliability of the instrument. The exploratory and confirmatory factor analyses yielded an 11-factor model, with 47 items distributed among them, and with good fit índices, $\mathrm{X}^{2}(979, N=1,854)$ $=4,643.93, p<.001 ; \mathrm{CFI}=.87$; SRMR $=.050$; RMSEA $=.045$ (90\% CI: .044, .046). The structural model was invariant and unidimensional for each subscale across the 15 samples (with exception of the community feeling, hedonism and popularity, that were not tested). The results showed acceptable levels of internal consistency across countries for the 11 domains of goals aspirations (with Cronbach's alphas ranging from .67 to .90). Finally, the authors demonstrated that a two-dimensional representation was appropriate to organize the goals. This representation tested how the intrinsic goals grouped together, while at the same time being opposite to the extrinsic goals, forming the horizontal dimension; and the spirituality and hedonism forming the basis for the orthogonal axis, with the self-transcendent goals being opposite to the physical ones.

However, although the study included two Latin-American countries, Dominican Republic and Colombia $(n=216)$, the sampling did not include data from Brazil where there is a great variability in cultural, social, and economic terms, which perhaps could lead to a different organization of the goal subscales (Owe et al., 2012). Adapting the AI to the Brazilian context would provide an instrument based on SelfDetermination scientific research to evaluate goals and their impact on other psychological, social and physical outcomes, through different stages in life, in Brazilian population.

Thus, the aims of this study were: (a) To conduct the cross-cultural adaptation process of the AI from the original English version to a Brazilian-Portuguese version; (b) To analyze psychometric properties of the new version of the instrument: internal consistency estimates, factor structure, and model invariance of each subscale, and to test the dimensionality of the model in order to understand the organization of the goal subscales in the Brazilian context. 


\section{Method}

\section{Participants}

Participants were 970 Brazilian young adults aged 18 to 30 years old $(56.8 \%$ women; $\left.M_{\text {age }}=22.8 ; S D=3.4\right)$, contacted trough an online questionnaire sent to three public and two private Brazilian Universities. The participants

\section{Table 1}

Socio Demographic Data from the Complete Sample gave their approval for participating in the research trough a consent declaration previously approved by the Ethics Committee of the Universidade Federal do Rio Grande do Sul (protocol number 246.001). All participants responded to a demographic questionnaire and to the adapted Brazilian-Portuguese version of the Aspiration Index (Grouzet et al., 2005). The demographic characteristics of the sample are presented in Table 1.

\begin{tabular}{lcc}
\hline & $N(971)$ & Percentage (\%) \\
\hline Age in years & 970 & $M=22.8, S D=3.4$ \\
Gender (feminine) & 549 & $56.8 \%$ \\
Socio-economic level & & \\
$\quad$ Low (up to R \$2000) & 87 & $25.7 \%$ \\
$\quad$ Middle (up to R $\$ 5000)$ & 248 & $38.8 \%$ \\
$\quad$ High (more than R $\$ 5000)$ & 301 & $31.2 \%$ \\
Educational level & & \\
$\quad$ Elementary school & 7 & $7 \%$ \\
$\quad$ High school & 86 & $2.6 \%$ \\
$\quad$ Bachelor (technique school or university) & 772 & $80 \%$ \\
$\quad$ Post-graduation (Master or Doctorate) & 99 & $10.3 \%$ \\
Working status & & \\
$\quad$ Student & 886 & $91.8 \%$ \\
Currently working & 600 & $62.2 \%$ \\
$\quad$ Never have worked before & 132 & $13.7 \%$ \\
$\quad$ Working in the business, trade or financial administrative & 110 & $11.4 \%$ \\
$\quad$ Working in the industry, factory or enterprises & 120 & $12.4 \%$ \\
Working in a NGO or public official & 114 & $11.8 \%$ \\
\hline
\end{tabular}

\section{Instruments}

The Aspiration Index has 47 statements divided into 11 goal domains representing: financial success (4 items; $\alpha=.83$ ); image (5 items; $\alpha=.74$ ); popularity ( 3 items; $\alpha=.71$ ); selfacceptance ( 7 items; $\alpha=.73$ ); physical health (4 items; $\alpha=.74$ ); affiliation (5 items; $\alpha=.75$ ); community feeling ( 3 items; $\alpha=.71$ ); spirituality (5 items; $\alpha=.87$ ); conformity ( 4 items; $\alpha=$
.62 ); hedonism (3 items; $\alpha=.72$ ) and; safety (4 items; $\alpha=.70$; Grouzet et al., 2005). Respondents indicate the importance of each goal for themselves on a 9-point scale from 1 (not important at all) to 9 (very important). They then indicate the probability they believe they have to achieve these goals on a 9-point scale from 1 (very little chance) to 9 (many chances). For the purposes of this study, only the importance answers will be analyzed. 


\section{Procedures}

Cross-Cultural Adaptation. The author of the original version of the instrument was contacted to give his approval for the adaptation and validation process of the instrument to the Brazilian context (Gjersing, Caplerhorn, \& Claussen, 2010; International Test Commission, 2010). After the consent of the author was given, we contacted three independent translators to translate the original English version to Brazilian-Portuguese. After that, we elaborated a synthesized translated version based on the three translations and sent it to be back-translated. All translators were fluent in English and were Brazilian natives. After this, a committee that included the author of the original version and three PhD Brazilian Psychologists evaluated the original version of the AI, along with the synthesized Brazilian-Portuguese and back-translated versions in terms of its suitability to the Brazilian context. Some items went through adjustments until an agreement between all the judges was reached (Borsa, Damásio, \& Bandeira, 2012).

Finally, we conducted a pilot study with 30 Brazilian youth to identify any problems with the wording, confusing language or ambiguous questions. We asked students to rephrase any items they considered confusing or not wellwritten into a more common form. In general, items were easily comprehended but some adjustments were needed in the instructions in order to further clarify the concepts of "importance" and "chances".

\section{Data Analysis}

We tested the sphericity of the sample using the Barlett's test and the factorability using the KMO measure, considering a value greater than .8 for sampling adequacy. After that, we conducted an internal consistency assessment for each subscale of the instrument, accepting a value of up to .60 for Cronbach's alpha given the complexity of the model structure.

To evaluate the factor structure of the model in the Brazilian context, we conducted a confirmatory factor analysis (CFA). The estimation method used was MLM (maximum likelihood mean adjusted), recommended for complex models with continuous variables (or categorical variables with more than five categories, as in this case), and tested the original proposed 11-factor model of the AI (Grouzet et al., 2005) using the Mplus software (Byrne, 2012). Due to the complexity of the model, we applied the decision rules of $\mathrm{Hu}$ and Bentler (1999) and consider as the main indicators of the goodness of fit of the model the WRMR $(<1.0)$ and the RMSEA $(\leq .05)$, and using the TLI $(>.95)$ and the CFI ( $>.95)$ only as complementary indicators (Fan \& Sivo, 2005; Hu \& Bentler, 1998).

Next, we carried out a multi-group confirmatory factor analysis (MGCFA), to test the configural invariance of the measure, accounting for the invariance in the number of factors and of items per factor (Damásio, 2012). Specifically, we tested one model for each one of the subscales, using the MLR estimator (Maximum Likelihood Estimator) with the whole sample (varying between 839 and 878 participants, due to missing data). Through this analysis, we aimed to assess whether the proposed structure is invariant across three different groups divided by their socio-economic status, as it could influence they interpretation of the goal domains (Piff, 2014). For these models, we used the SRMR ( $\leq$ $.08)$ as a principal indicator, the RMSEA $(\leq .05)$, the TLI $(>.90)$ and the CFI $(>.90)$ as complementary indicators (Hu \& Bentler, 1998).

Finally, we examined if the data from the Brazilian sample could be organized in a similar two-dimension structure as showed in the research by Grouzet and colleagues (2005). Thus we performed a multi-dimensional scaling modeling (MDS), which allows us to present a spatial representation of the goal factor structure in which the distance between the points reflects the empirical relations among the goals (Bushmakin, Cappelleri, Symonds, \& Stecher, 2014). This technique complements the interpretation of the latent structure of the measurement model, because instead of assuming a linear relationship between the variables as in the CFA, the MDS considers the rank order of the points of each variable on the space, establishing patterns that were not obvious previously (Dillon \& Goldstein, 1984). 
For this aim, we examined the stress indicators such as the scree plot and the $R^{2}$ to analyze the solutions from one to four dimension plots. We then used the standardized factor scores of each subscale to calculate the distance among the points, using the Euclidean distance formula. With these distances among the 11 goals factor we build the proximity matrix, which was used as an input for drawing the graphic representation of the data using the MDS (Hair, Black, Babin, Anderson, \& Tatham, 2009). Through this analysis, we expected to verify three hypotheses: (a) certain goals are more compatible with some, while being opposite to others; (b) one of the two dimensions underlying the organization of the subscales will be compatible with intrinsic and extrinsic structure previously defined; and (c) two of the other goal domains considered (hedonism, conformity, spirituality, and safety) would define the second dimension.

\section{Results}

The results for the Bartlett's test $\left(X^{2}=\right.$ $16,173.21, p<.001)$ and the $\mathrm{KMO}=.91$ showed the adequacy and factorability of the sample. The reliability assessment showed good Cronbach's alphas for each one of the subscale scores, ranging from .57 to .94 as can be seen in Table 2 .

Table 2

Goal Domain, Number and Example of Items, and Reliability Assessment for Each Subscale of the Aspiration Index's Brazilian Version

\begin{tabular}{|c|c|c|c|}
\hline Goal domain & $\begin{array}{l}\text { Number } \\
\text { of items }\end{array}$ & Example of item & $\begin{array}{l}\text { Reliability } \\
(\text { Cronbach } \alpha)\end{array}$ \\
\hline Self-acceptance & 7 & "I will have insight into why I do the things I do." & .73 \\
\hline Affiliation & 5 & "I will have a committed, intimate relationship." & .76 \\
\hline Sense of community & 3 & "I will assist people who need it, asking nothing in return." & .82 \\
\hline Health & 4 & "I will be physically healthy." & .77 \\
\hline Financial success & 4 & "I will be financially successful." & .82 \\
\hline Popularity & 3 & "I will be admired by many people." & .74 \\
\hline Image & 5 & "My image will be one other's find appealing." & .84 \\
\hline Conformity & 4 & "I will live up to the expectations of my society." & .74 \\
\hline Spirituality & 5 & $\begin{array}{l}\text { "I will find religious or spiritual beliefs that help me make } \\
\text { sense of the world." }\end{array}$ & .94 \\
\hline Safety & 4 & "I will have few threats to my personal safety." & .57 \\
\hline Hedonism & 3 & "I will have a great sex life." & .63 \\
\hline
\end{tabular}

Note. $N=971$.

Cases that presented missing data were excluded from the CFA. Thus, 839 cases remained accounting for more than 10 individuals per item, which is considered adequate for the CFA (Hair et al., 2009; Hogarty, Hines, Kromey, Ferron, \& Mumford, 2005). The CFA results demonstrated a good fit for the 11-factor model in the Brazilian context, $X^{2}(d f=978)=3,318.64$, $p<.001 ;$ WRMR $=1.578$; RMSEA $=.053, p<$ $.05 ; \mathrm{CFI}=.956 ; \mathrm{TLI}=.951$.

To perform the multi-group CFA, we divided our sample in three groups by their socio-economical level, accounting for their total income and their parent's educational 
level (Alves \& Soares, 2009). The final model of each goal subscale was evaluated using a model that assumes equal factor loading and intercepts, and considers the variable as continuous (using categorical variables with strong intercorrelations would prevent the software from identifying possible variability in the sample). Results showed CFI and TLI values above .90 , and RMSEA values below the cutoff point of .06 for almost all the models, from which we can assume the invariance of the factor structure for all subscale models across the different groups (Table 3). The "health" and "safety" subscales showed lower fit indexes, but still in the acceptable range of discrimination.

Table 3

Multi-Group Confirmatory Factor Analysis for Each Aspiration Index Sub-Scale

\begin{tabular}{lcccccccc}
\hline & & \multicolumn{3}{c}{ SB chi-squared } & & \multicolumn{3}{c}{ Absolute fit indexes } \\
\cline { 3 - 8 } \multicolumn{1}{c}{ Sub-scale } & Items & $x^{2}$ & $d f$ & $p$ & CFI & TLI & SRMR & RMSEA \\
\hline Self-acceptance & 7 & $84.601^{*}$ & 66 & .06 & .965 & .967 & .092 & .031 \\
Affiliation & 5 & $30.799^{*}$ & 31 & .47 & .984 & 1.00 & 1.00 & .001 \\
Sense of community & 3 & $15.401^{*}$ & 8 & .03 & .981 & .981 & .076 & .059 \\
Health & 4 & $49.440^{*}$ & 18 & .001 & .946 & .946 & .086 & .077 \\
Financial success & 4 & $47.484^{*}$ & 18 & .002 & .960 & .960 & .058 & .075 \\
Popularity & 3 & $10.623^{*}$ & 8 & .22 & .993 & .993 & .039 & .033 \\
Image & 5 & $94.316^{*}$ & 31 & .001 & .947 & .949 & .063 & .074 \\
Spirituality & 5 & $60.594^{*}$ & 31 & .001 & .982 & .983 & .040 & .057 \\
Conformity & 4 & $34.049^{*}$ & 18 & .012 & .974 & .974 & .051 & .055 \\
Safety & 5 & $51.097^{*}$ & 31 & .013 & .939 & .941 & .104 & .047 \\
Hedonism & 5 & $5.650^{*}$ & 8 & .686 & 1.00 & 1.02 & .048 & .001 \\
\hline
\end{tabular}

${ }^{*} p<.01$.

The correlation results (Table 4) showed moderate positive correlations among the intrinsic goals domains (self-acceptance, affiliation and sense of community), and among the extrinsic goals (financial success, popularity and image), with an $r \geq .55$. The correlations between intrinsic and extrinsic domains were positive but weak, except for the correlation between the affiliation and the popularity domains $(r=.412)$. However, there were also moderate to strong correlations between the factors of self-acceptance, health and safety (with $r$-values between .49 and .62).

Next, we conducted the MDS analysis by portraying the one through four dimension plots and evaluating the solutions. The stress plot and the stress indicators ( S-stress $=.2895$ ) showed that the second dimension improved the fit of the model $(\Delta$ stress $=.36)$, and there was no significant improvement after the second dimension was added $(\Delta$ stress $=.05)$. Furthermore, the Tucker's coefficient of congruence of 962 supported the two dimensions model for the Brazilian sample as hypothesized.

With the two-dimensional distribution being established, we used the standardized factor scores of each subscale and calculated the Euclidean distances between each factor to create a proximity matrix. We performed the MDS analysis using these distances as data and obtained the representation in Figure 1. 
Table 4

Means, Standard Deviation and Correlations between the Aspirations Index Factors

\begin{tabular}{|c|c|c|c|c|c|c|c|c|c|c|c|c|c|}
\hline & $M$ & $S D$ & $\mathrm{~F} 1$ & $\mathrm{~F} 2$ & F3 & $\mathrm{F} 4$ & F5 & F6 & F7 & F8 & F9 & F10 & F11 \\
\hline F1-Self-acceptance & 56.73 & 5.74 & 1 & & & & & & & & & & \\
\hline F2-Affiliation & 40.12 & 5.63 & $.468 *$ & 1 & & & & & & & & & \\
\hline $\begin{array}{l}\text { F3-Sense of } \\
\text { community }\end{array}$ & 23.40 & 4.375 & $.434^{*}$ & $.463 *$ & 1 & & & & & & & & \\
\hline F4-Health & 30.10 & 5.38 & $.522 *$ & $.318^{*}$ & $.323 *$ & 1 & & & & & & & \\
\hline $\begin{array}{l}\text { F5-Financial } \\
\text { success }\end{array}$ & 26.26 & 6.06 & $.379 *$ & $.239 *$ & .019 & $.389 *$ & 1 & & & & & & \\
\hline F6-Popularity & 18.55 & 5.05 & $.370 *$ & $.412 *$ & $.275^{*}$ & $.297 *$ & $.493^{*}$ & 1 & & & & & \\
\hline F7-Image & 25.36 & 9.46 & $.271 *$ & $.301 *$ & $.127 *$ & $.413 *$ & $.605^{*}$ & $.620 *$ & 1 & & & & \\
\hline F8-Spirituality & 24.62 & 13.98 & $.201 *$ & $.286^{*}$ & $.338^{*}$ & $.122 *$ & $.142 *$ & $.238^{*}$ & $.253 *$ & 1 & & & \\
\hline F9-Conformity & 20.97 & 7.06 & $.292 *$ & $.410^{*}$ & $.314^{*}$ & $.293 *$ & $.434 *$ & $.532 *$ & $.536^{*}$ & $.388^{*}$ & 1 & & \\
\hline F10-Safety & 31.35 & 4.35 & $.620 *$ & $435^{*}$ & $.306^{*}$ & $.482 *$ & $.356^{*}$ & $.282 *$ & $.264^{*}$ & $.275^{*}$ & $.083 *$ & 1 & \\
\hline F11-Hedonism & 22.65 & 3.86 & $.486^{*}$ & $483 *$ & $.375^{*}$ & $.403 *$ & $.364^{*}$ & $.403^{*}$ & $.369 *$ & $.311 *$ & $.141^{*}$ & $.373 *$ & 1 \\
\hline
\end{tabular}

Note. $N=971$.

$* p<.01$.

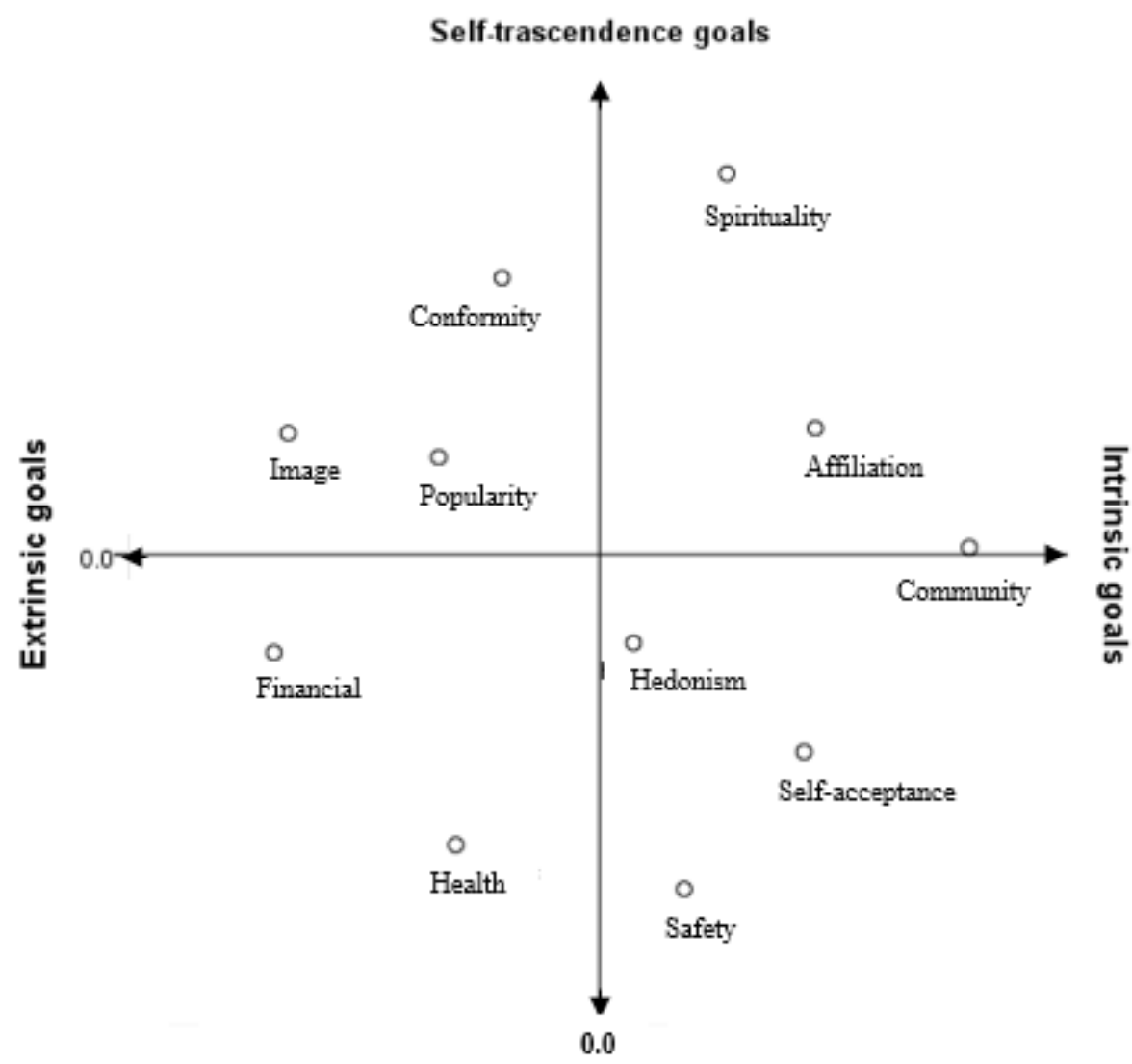

Physical goals

Figure 1. Two-dimensional representation of the goal factors resulting from the MDS of the Aspiration Index in the Brazilian context. 


\section{Discussion}

The aims of this study were to describe the cross-cultural adaptation of the AI to Brazil and to evaluate the psychometric properties of the Brazilian-Portuguese version, including internal consistency, factor structure, measurement invariance across socioeconomic groups, and the dimensionality of the instrument in the Brazilian context. The results presented here suggest that the Aspiration Index is a reliable measure to assess different types of life goals and rate their importance and chances of achievement in the Brazilian population.

Through the adaptation process, we achieved an instrument considered suitable at both linguistic and cultural levels for the Brazilian context. Both the results from the reviewers' evaluation and the pilot study yielded positive evidence of the adaptation process, allowing us to continue with the analysis of the psychometric properties. The analysis showed a good internal consistency of all subscales. The CFA results showed that the eleven factor model was suitable for the Brazilian context with good indicators of goodness of fit.

The MGCFA demonstrated invariance of the factor structure of the eleven subscale models, with CFI and TLI values above .90, RMSEA values below .08 and SRMR values below .09, which is considered acceptable or good for all of them (Hu \& Bentler, 1998). Although the RMSEA values were slightly beyond the expected for the acceptance of the model, this result should be interpreted with parsimony, since the cutoff point may depend on the degrees of freedom of the model and the sample size (Chen, Curran, Bollen, \& Paxton, 2008). Our results support the assumption that the AI is reliable and its structure is sufficiently invariant across different socio-economic groups.

In addition, using the MDS, we portrayed a graphic representation of the data, using the dissimilarities of the eleven subscales (calculated by the Euclidean distance) in order to visualize information and explore these dissimilarities. As we can see in Figure 1, the structure of the instrument is organized in a bidimensional way, which is consistent with results from previous research (Grouzet et al., 2005). The horizontal dimension was defined by the division in intrinsic goals (affiliation, self-acceptance and sense of community) and extrinsic goals (financial success, image and popularity) as hypothesized, and supported by previous the Self-Determination Theory studies (Deci \& Ryan, 2012; Van Hiel \& Vansteenkiste, 2009).

On the other hand, the vertical dimension was defined by the spirituality (named as selftranscendent goals) and by the safety and health factors (named as physical goals) in the opposite extreme of the diagram. Although these results satisfy our hypothesis that one of the other goal domains (hedonism, conformity, spirituality and safety) would define the second dimension; they are differ from previous research (Grouzet et al., 2005). Previous graphic representation showed the health subscale along the intrinsic side, but in our sample, this subscale presented a more extrinsic and physical character (Figure 1). The correlation analysis also showed that the health subscale had good and significant correlations with the image ( $r=.413)$, safety $(r=.482)$ and hedonism $(r=.403)$ subscales.

These results are more compatible with the view about physical health portrayed by the wealthier cultures in the MDS analysis of the study of Grouzet and colleagues (2005). Considering that Brazil is the second country where most cosmetic surgical procedures are performed annually worldwide (Dearden, 2014), the prevalence of body image dissatisfaction is around $25.3 \%$, and the prevalence of anorexia and bulimia symptoms is around $20 \%$, considering the mean of three studies with Brazilian population (Alves, Vasconcelos, Calvo, \& Neves, 2008; Fiates \& Salles, 2001; Martins, Pelegrini, Matheus, \& Petroski, 2010), still higher than the international average. It is possible to understand that in this context the physical health would be related to ideas of image and physical appearance, hedonism and safety. However, it is necessary to conduct more research in order to understand these results 
and its implications in the Brazilian population. However, the moderate correlations between self-acceptance, health and safety, indicate that this association also deserves more attention in future research.

Another result that appeared in the Brazilian representation was that the hedonism factor was also allocated in the intrinsic side of the graphic, which is compatible with the wealthier cultures representation of goals in the Grouzet et al. (2005) study. However, this factor appeared to define the physical dimension of previous analysis, but for the Brazilian sample, it is located almost at the center of the diagram, without tending to any end of the dimensions. Some research has been conducted with respect to hedonism as a motivational value (Tamayo, 2009; Tamayo, Lima, Marques, \& Martins, 2001), but so far there is not enough evidence to better understand this finding.

Thus, any future research with the AI might benefit from including instruments that evaluate constructs such as meaning in life (Brassai, Piko, \& Steger, 2012; Damásio \& Koller, 2013) and motivational values (Schwartz, 2012; Tamayo, 2009). Given that, these aspects are important and intimately related to the way people choose to live their lives, and thus, help establishing the goals that are important to follow by the individual. On the other hand, it would also be interesting to include different indicators of well-being and verify how they relate to the different types of goals: intrinsic, extrinsic, selftranscendence or physical ones.

Finally, this instrument may be useful in future research and psychosocial interventions and can be used in a wide variety of age groups and contexts within Brazil. The acknowledgment of the goals which are most important for Brazilian youth in different contexts (e.g., educational and socioeconomic level, working status, etc.) would help to elaborate more adequate psychological and social interventions to foster their wellbeing. Finally, the instrument could also serve as a guide to organize psychological interventions for career counseling and formulate public and private policies in schools and universities to enhance more positive goals.

\section{References}

Alves, E., Vasconcelos, F. A. G., Calvo, M. C. M., \& Neves (2008). Prevalência de sintomas de anorexia nervosa e insatisfação com a imagem corporal em adolescentes do sexo feminino do Município de Florianópolis, Santa Catarina, Brasil. Cadernos de Saúde Pública, 24(3), 503512. doi:10.1590/S0102-311X2008000300004

Alves, M. T. G., \& Soares, J. F. (2009). Medidas de nível socioeconômico em pesquisas sociais: Uma aplicação aos dados de uma pesquisa educacional. Opinião Pública, (Campinas), 15(1), 1-30. doi:10.1590/S0104-62762009000100001

Borsa, J. C., Damásio, B. F., \& Bandeira, D. R. (2012). Adaptação e validação de instrumentos psicológicos. Paidéia (Ribeirão Preto), 22(53), 423-432. doi:10.1590/S0103863X2012000300014

Brassai, L., Piko, B. F., \& Steger, M. F. (2012). Existential attitudes and eastern European adolescents' problem and health behavior highlighting the role of the search for meaning in life. The Psychological Rocord, 62, 719-734.

Burke, B. L., Martens, A., \& Faucher, E. H. (2010). Two decades of Terror Management Theory: A meta-analysis of mortality salience research. Personality and Social Psychology Review, 14(2), 155-195. doi:10.1177/1088868309352321

Bushmakin, A. G., Cappelleri, J. C., Symonds, T., \& Stecher, V. J. (2014). Further understanding of the International Index of Erectile Function at 15+ years: Confirmatory factor analysis and multidimensional scaling. Therapeutic Innovation \& Regulatory Science, 48(2), 246-254. doi:10.1177/2168479013500056

Byrne, B. (2012). Structural equation modeling with Mplus, basic concepts, applications and programming. New York: Taylor \& Francis Group.

Chen, F., Curran, P. J., Bollen, K., \& Paxton, P. (2008). An empirical evaluation of the use of fixed cutoff points in RMSEA test statistic in structural equation models. Sociological Research Methods, 36(4), 462-494. doi:10.1177/0049124108314720

Cialdini, R. B., \& Goldstein, N. J. (2004). Social Influence: Compliance and conformity. Annual Review of Psychology, 55, 591-621. doi:10.1146/ annurev.psych.55.090902.142015 
Damásio, B. F. (2012). Uso da análise fatorial exploratória em psicologia. Avaliação Psicológica, 11(2), 213-228.

Damásio, B. F., \& Koller, S. H. (2013). Validation and psychometric properties of the Brazilian version of the meaning in life quetionnaire (MLQ). Unpublished manuscript, Universidade Federal do Rio Grande do Sul, Porto Alegre, RS, Brazil.

Dearden, L. (2014, July). Top 10 countries for cosmetic surgery revealed. In The Independent. Retrieved from http://www.independent.co.uk/ life-style/health-and-families/health-news/top10-countries-for-cosmetic-surgery-revealedas-figures-show-industry-is-booming-worldwide-9636861.html

Deci, E., \& Ryan, R. M. (2000). The "what" and "why" of goal pursuits: Human needs and the self-determination of behavior. Psychological Inquiry, 11(4), 227-268. doi:10.1207/ S15327965PLI1104 01

Deci, E., \& Ryan, R. M. (2008). Hedonia, eudemonia, and well-being: An introduction. Journal of Happiness Studies, 9(1), 1-11. doi:10.1007/ s10902-006-9018-1

Deci, E., \& Ryan, R. M. (2012). Motivation, personality, and development within embedded social context: An overview of SelfDetermination Theory. In M. R. Ryan (Ed.), Oxford handbook of human motivation (pp. 85107). Oxford, UK: Oxford University Press.

Dillon, W. R., \& Goldstein, M. (1984). Multivariate Analysis: Methods and applications. New York: John Wiley \& Sons.

Emmons, R. A. (2003). Personal goals, life meaning, and virtue: Wellsprings of a positive life. In C. L. Keyes \& J. Haidt (Eds.), Flourishing: Positive psychology and the life well-lived (pp. 105128). Washington, DC: American Psychological Association. doi:10.1037/10594-005

Espíndula, J. A., Do Vale, E. R. M., \& Bello, A. A. (2010). Religion and spirituality: The perspective of health professionals. Revista LatinoAmericana de Enfermagem, 18(6), 1229-1236. doi:10.1590/S0104-11692010000600025

Fan, X., \& Sivo, S. (2005). Sensitivity of fit indexes to misspecified structural or measurement model components: Rationale of two-index strategy revisited. Structural Equation Modeling, 12(3), 343-367. doi:10.1207/s15328007sem1203_1
Fiates, G. M. R., \& Salles, R. K. (2001). Fatores de risco para o desenvolvimento de distúrbios alimentares: Um estudo em universitárias. Revista de Nutrição, 14, 3-6. doi:10.1590/ S1415-52732001000400001

Gjersing, L., Caplehorn, J. R., \& Claussen, T. (2010). Cross-cultural adaptation of research instruments: Language, setting, time and statistical considerations. BCM Medical Research Methodology, 10(13), 2-10. doi:10.1186/1471-2288-10-13

Grouzet, F. M. E., Kasser, T., Ahuvia, A., Dols, J. M., Kim, Y., Lau, S., ...Sheldon, K., M. (2005). The structure of goal content across 15 cultures. Journal of Personality and Social Psychology, 89(5), 800-816. doi:10.1037/0022-3514.89.5.800. 800

Hair, J. F., Black, W. C., Babin, B. J., Anderson, R. E., \& Tatham, R. L. (2009). Multivariate data analysis ( $7^{\text {th }}$ ed.). New York: Prentice Hall.

Hogarty, K. Y., Hines, C. V., Kromey, J. D., Ferron, J. M., \& Mumford, K. R. (2005). The quality of factor solution in exploratory factor analysis: The influences if sample size, communality, and over determination. Educational and Psychology Measurement, 65(2), 202-226. doi:10.1177/0013164404267287

Hu, L., \& Bentler, P. M. (1998). Fit indices in covariance structure modeling: Sensitivity to underparameterized model misspecification. Psychological Methods, 3(4), 424-453. doi:10.1037/1082-989X.3.4.424

Hu, L., \& Bentler, P. M. (1999). Cutoff criteria for fit indexes in covariance structure analysis: Conventional criteria versus new alternatives. Structural Equation Modeling, 6(1), 1-55.

International Test Commission. (2010). International Test Commission guidelines for translating and adapting tests. Retrieved from http://www. intestcom.org/upload/sitefi les/40.pdf

Kasser, T. (2011). Commissioned paper: Values and human wellbeing. Galesburg, IL: Knox College.

Kasser, T., \& Ryan, R. M. (1993). A dark side of American dream: Correlates of financial success as a central life aspiration. Journal of Personality and Social Psychological, 65(2), 410-422. doi:10.1037/0022-3514.65.2.410

Kasser, T., \& Ryan, R. M. (1996). Further examining the American dream: Differential correlates of intrinsic and extrinsic goals. Personality and Social Psychology Bulletin, 22(3), 280-287. doi:10.1177/0146167296223006 
Kasser, T., \& Ryan, R. M. (2001). Be careful what you wish for: Optimal functioning and the relative attainment of intrinsic and extrinsic goals. In P. Schmuck \& K. M. Sheldon (Eds.), Life goals and wellbeing: Towards a positive psychology of human striving (pp. 116-131). Goettingen, Germany: Hogrefe \& Huber.

Martins, C. R., Pelegrini, A., Matheus, S. C., \& Petroski, E. L. (2010). Insatisfação com a imagem corporal e relação com estado nutricional, adiposidade corporal e sintomas de anorexia e bulimia em adolescentes. Revista Psiquiátrica do Rio Grande do Sul, 32(1), 19-23. doi:10.1590/ S0101-81082010000100004

Owe, E., Vignoles, V. L., Becker, M., Brown, R., Smith, P. B., Lee, S. W., ...Jalal, B. (2012). Contextualism as an important facet of individualism-collectivism: Personhood beliefs across 37 national groups. Journal of Cross-Cultural Psychology, 41(1), 24-45. doi:10.1177/0022022111430255

Piff, P. K. (2014). Wealth and inflated self: Class, Entitlement, and Narcissism. Personality and Social Psychology Bulletin, 40(1), 34-43. doi:10.1177/0146167213501699

Schwartz, S. H. (2012). An overview of the Schwartz theory of basic values. Online Reading in Psychology and Culture, 2(1). doi:10.9707/23070919.1116

Tamayo, A. (2009). Validação do questionário de perfis de valores (QPV) no Brasil. Psicologia: Teoria e Pesquisa, 25(3), 369-376. doi:10.1590/ S0102-37722009000300010

Tamayo, A., Lima, A., Marques, J., \& Martins, L. (2001). Prioridades axiológicas e uso de preservativos. Psicologia: Reflexão e Crítica, 14(1), $167-175$.
Vail, K. E., III, Juhl, J., Arndt, J., Vwheness, M., Routledge, C., \& Rutjens, B. T. (2012). When death is good for life: Considering the positive trajectories of terror management. Personality and Social Psychology Review, 16, 1-27. doi: $10.1177 / 1088868312440046$

Van Hiel, A., \& Vansteenkiste, M. (2009). Ambitious fulfilled? The effects of intrinsic and extrinsic goal attainment on older adults' ego-integrity and death attitudes. The International Journal of Aging and Human Development, 68(1), 27-51. doi:10.2190/ag.68.1.b

Van Ijzendoorn, M. H., \& Sagi-Schwartz, A. (2008). Cross-cultural patterns of attachment: Universal and contextual dimensions. In J. Cassidy \& P. Shaver (Eds.), Handbook of attachment, theory, research, and clinical applications $\left(2^{\text {nd }}\right.$ ed., $\mathrm{pp}$. 880-905). New York: The Guilford Press.

Vansteenkiste, M., Lens, W., \& Deci, E. L. (2006). Intrinsic versus extrinsic goal-contents in Self-Determination Theory: Another look at the quality of academic motivation. Educational Psychologist, 41, 19-31. doi:10.1207/ s15326985ep4101 4 